\title{
The promoter regions of the Myb-regulated Adora2B and Mcm4 genes co-localize with origins of DNA replication Holger Gundelach $^{\dagger 1}$, Daniel Braas ${ }^{\dagger 1,2}$ and Karl-Heinz Klempnauer*1
}

\author{
Address: ${ }^{1}$ Institute for Biochemistry, Westfälische-Wilhelms-Universität Münster, Wilhelm-Klemm-Str. 2, D-48149 Münster, Germany and \\ ${ }^{2}$ Howard Hughes Medical Institute, MacDonald Research Laboratories, UCLA, 675 Charles E. Young Drive South, Los Angeles, CA-90095-1662, \\ USA \\ Email: Holger Gundelach - hogul@uni-muenster.de; Daniel Braas - dbraas@microbio.ucla.edu; Karl-Heinz Klempnauer* - klempna@uni- \\ muenster.de \\ * Corresponding author †Equal contributors
}

Published: 6 September 2007

BMC Molecular Biology 2007, 8:75 doi:10.1186/147|-2199-8-75

This article is available from: http://www.biomedcentral.com/I47I-2199/8/75

(c) 2007 Gundelach et al; licensee BioMed Central Ltd.

This is an Open Access article distributed under the terms of the Creative Commons Attribution License (http://creativecommons.org/licenses/by/2.0), which permits unrestricted use, distribution, and reproduction in any medium, provided the original work is properly cited.
Received: 27 February 2007

Accepted: 6 September 2007

\begin{abstract}
Background: The retroviral oncogene v-myb encodes a transcription factor ( $v$-Myb) which is responsible for the transformation of myelomonocytic cells by avian myeloblastosis virus (AMV). $\mathrm{v}$-Myb is thought to exert its biological effects by deregulating the expression of specific target genes. We have recently demonstrated that the chicken Gas 4 I gene, whose promoter co-localizes with an origin of DNA replication, is a bona fide Myb target gene. Because of this finding we have asked whether other Myb-regulated genes are also associated with DNA replication origins.
\end{abstract}

Results: We show that the promoter region of the chicken adenosine receptor 2B gene (Adora2B), a known Myb-target gene, acts as a DNA replication origin. Furthermore, we have examined known replication origins for the presence of Myb binding sites. We found that the intergenic region between the genes for the minichromosome maintenance 4 protein $(\mathrm{Mcm} 4)$ and the catalytic subunit of DNA-dependent protein kinase (Prkdc), whose human counterpart has been identified as a replication origin, contains a number of Myb binding sites. Our data show that this region also acts as an origin of replication in chicken cells. Interestingly, we found that the chicken $\mathrm{Mcm} 4$ gene is also Myb-regulated.

Conclusion: Our work identifies the chicken $\mathrm{Mcm} 4$ gene as a novel Myb target gene and presents evidence for the co-localization of two novel origins of DNA replication with Myb-regulated genes. Our work raises the possibility that a fraction of Myb target gene promoters is associated with DNA replication origins.

\section{Background}

The oncogene v-myb of avian myeloblastosis virus (AMV) encodes a transcription factor which is responsible for the ability of AMV to transform cells of the myelomonocytic lineage $[1,2] . \mathrm{v}-m y b$ is derived from the chicken c-myb gene, which plays a crucial role in the development of the hematopoietic system. c-myb is expressed in immature cells of all hematopoietic lineages and is silenced during the terminal differentiation of these cells. It is thought that $c-m y b$ is part of a genetic switch that allows hematopoietic progenitor cells to choose between alternative fates, such as proliferation, differentiation or apoptosis $[2,3]$. 
The proteins encoded by v- $m y b$ and c-myb (v-Myb and cMyb) bind to the sequence motif PyAAC $(\mathrm{G} / \mathrm{T}) \mathrm{G}[4]$ and control the expression of a number of genes, such as mim$1[5]$, the lysozyme gene [6], bcl-2 [7,8], tom-1 [9], c-kit [10], GBX2 [11], Pdcd4 [12], the genes for neutrophil elastase [13] and the A2B adenosine receptor [14] among others. Recent microarray analyses have suggested that Myb actually affects the expression of a much larger set of genes, either by direct binding or by indirect mechanisms [15].

Most of the work aimed at understanding how Myb activates the expression of its target genes has focused on the promoter regions of these genes and has provided a relatively simple picture of how Myb affects gene expression. In many cases, Myb binding sites have been identified in the promoter regions of these genes, suggesting that Myb acts primarily on the promoters of its targets. Recent indepth analyses of some Myb target genes, however, have suggested a more complex picture in which the activation of certain target genes is mediated by cooperation of additional Myb-responsive enhancer elements with the target gene promoters. For example, the expression of the chicken mim-1 gene is controlled by interactions of Myb both with the promoter as well as with a powerful cellspecific enhancer located upstream of the gene [16]. Similarly, in case of the chicken C/EBP $\beta$ gene Myb targets the promoter as well as an enhancer located downstream of the gene [17].

Recently, another regulatory DNA element has been mapped close to a Myb-regulated gene. We have shown that chicken Gas41, whose promoter region has been known for some time to act as an origin of DNA replication $[18,19]$, is a direct Myb target gene [20]. Other work has shown that the Myb homolog of Drosophila melanogaster is involved in the control of the replication origin responsible for chorion gene amplification [21]. These observations raised the question of whether DNA replication origins are also associated with other Myb target genes. Here, we demonstrate that the promoter region of the Myb-regulated chicken adenosine receptor 2B gene acts as an origin of DNA replication. Furthermore, we identify the chicken $\mathrm{Mcm} 4$ gene as a novel Myb target gene and demonstrate that the Mcm4 promoter is associated with a replication origin. Besides identifying two new DNA replication origins in chicken cells and a novel Mybregulated gene our work suggests that a significant fraction of Myb-regulated genes might be associated with DNA replication origins.

\section{Results}

\section{The chicken Mcm4 gene is a Myb target gene}

The observation that the promoter of the Myb-regulated the chicken Gas41 gene [20] is associated with an origin of
DNA-replication $[18,19]$ prompted us to explore the possibility that other Myb target regions also co-localize with DNA replication origins. Ladenburger et al [22] have previously identified a replication origin located between the human Mcm4 and Prkdc genes. Both genes are separated from each other by an intergenic region of only $0.8 \mathrm{~kb}$ and are transcribed in opposite directions. This arrangement is conserved among humans, mice and chickens $[23,24]$. We noted that the corresponding chicken sequence contains a number of potential Myb binding motifs (Fig. 1). One of the sites (MBS-6) matched exactly to the consensus Myb binding motif PyAAC(G/T)G [4], while the other sites had one (MBS-4, MBS-1) or two (MBS-2, MBS-3 and MBS-5) mismatches. The human Mcm4-Prkdc intergenic region also contains 8 potential Myb binding motifs although their exact positions are not conserved between the human and the chicken sequence. To demonstrate that Myb recognizes at least some of the motifs found in the chicken sequence those sites (MBS-1, MBS-4 and MBS-6) that showed the best fit to the consensus binding motif were analyzed by electrophoretic mobility shift assays (EMSA) using recombinant $\mathrm{v}-\mathrm{Myb}$ protein expressed in bacteria. As illustrated in Fig. 2A, retarded protein-DNA complexes were observed when oligonucleotides containing MBS- 1, MBS- 4 and MBS- 6 were used, demonstrating that $\mathrm{v}-\mathrm{Myb}$ is able to recognize at least three of the potential binding sites in vitro. To confirm the specificity of binding we performed a competition experiment in which binding of $\mathrm{v}-\mathrm{Myb}$ to a radiolabeled oligonucleotide containing the high affinity Myb binding site A from the mim1 promoter [5] was competed by excess of unlabeled oligonucleotides containing MBS-1, MBS- 4 and MBS- 6 (Fig. 2B). Binding was competed efficiently by the mim-1 A site itself but not by a control oligonucleotide containing a $\mathrm{C} /$ EBP binding site. Oligonucleotides containing MBS- 4 and MBS- 6 also competed, although less efficiently that the mim-1 A oligonucleotide. MBS-1 appeared not to compete specifically with the mim-1 A site. Taken together, this experiment confirmed that $\mathrm{v}$-Myb binds specifically to binding sites 4 and 6 while binding to MBS- 1 was quite weak.

To investigate whether v-Myb is bound to the Mcm4 promoter region in vivo we performed chromatin immunoprecipitation (ChIP) experiments using the v-Myb transformed myeloblast line BM2. The cells were formaldehyde-fixed and DNA-protein complexes obtained after sonication were immunoprecipitated with two different antibodies against Myb. As a control, parallel incubations with non-immune serum or with unrelated antibodies were performed. After reverse-crosslinking and purification of the immunoprecipitated DNA the samples were analyzed by quantitative real-time PCR using the primers that bind to the Mcm4-Prkdc intergenic region or control primers. The result of the ChIP experiment is illustrated in 
81 AtCTtGCGGGGTCGGCGGGTTGCTGCCTCGCCCGCGCTTGCCGCGCCGGCGGCTGGGCGTGGAGGCGGGANACGACATAG MBS-6

161 CGCTGCCACAACGGTCCTACCGCGGGAGAGGAGCGCTGACGGCGGCTGAACCCCAAAATGGCGGCGCTCCCCCTATGCCC

241 CGCACGGCACCGATCGCGCACCCCTACACTCCGCACACCGGCGAACTCCCGCGCCGCCAGAGTCACGTGACCGCGCTCTC

321 GCGGGCTTTCTGGCCAATGGGTGCGCGCAGCGGCACCGGGATCTCCCACATGATAGGGAAAGGGGGGGGGCTCGGTCTGC

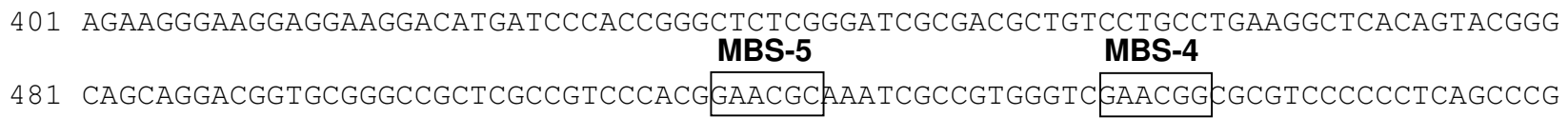

561 GAGTGGTACCGCCCGCAGTGGATGGAgTTTCGCGGCA AAACGA GTCCTGCGGGCGGGTCGGGAGGAGCGGCCCATTCTCT MBS-3

641 GTGAGGACGGGTGGGTGGTGTTTGCTGGTCACTATAGACGACTTTCCGGAGAGACAGAAATCCTACATAGCCCTTCTCTA MBS-2

721 CACATCCTTGCCCTATTGAAACGATTCGCCCAGCGCCTGCCCGCCGTCCTCCTTCCTCAGAGCGCGCCCACTCGGATACA MBS-1

801 ACAGAACCCTCCCCCCCCATCCTCCCGGGCA GCGTTGGGTCAGTCCGAGGGGCGGCTCCTCCCCGCCCGCTGCGCGCACT $\longrightarrow P R K D C$

881 GAGCGGGATGGCGGGCGGCGTTCAGGAGTGCCTCCAGGAGCTGCACGGCTGCCTGCAGCCCGGCGATGCCATGCGCGGC T

\section{Figure I}

Nucleotide sequence of the Mcm4-Prkdc intergenic region. The translational start codons of the Mcm4 and Prkdc genes are marked by arrowheads. Potential Myb binding sites are marked by boxes.

Fig. 3. We observed substantial enrichment of the Mcm4Prkdc intergenic region in samples precipitated with the Myb-specific antibodies, whereas control immunoprecipitations with non-immune sera or unrelated antibodies showed no specific enrichment. PCR-reactions with control primers that were specific for sequences located 13 kilobasepairs upstream of Mcm4 did not show significant enrichment in any of the immunoprecipitations. Taken together, the ChIP experiment clearly showed that v-Myb was bound to the Mcm4-Prkdc intergenic region in vivo.

Next, we investigated whether v-Myb also affected the expression of the Mcm4 or Prkdc genes. To address this issue we made use of a cell line, designated 10.4, which stably expresses a v-Myb/estrogen receptor fusion protein [25]. Upon $\beta$-estradiol treatment of 10.4 cells the v-Myb/ ER fusion protein is activated and upregulates the expression of a number of Myb target genes. 10.4 cells were cultivated for 24 hours in the presence or absence of $2 \mu \mathrm{M} \beta$ - estradiol. Polyadenylated RNA from these cells was then isolated and analyzed by Northern blotting with probes specific for Mcm4 or Prkdc mRNA. As a control, a probe hybridizing to the ribosomal protein S17 mRNA was used. As shown in Fig. 4, the Mcm4 mRNA level was elevated in the estrogen-treated 10.4 cells when compared to untreated cells, suggesting that chicken Mcm4 is indeed a Myb target gene. By contrast, Prkdc was not regulated by vMyb. 10.4 cells do not express endogenous estrogen receptor [25], suggesting that Mcm4 is not simply an estrogen-regulated gene.

\section{An origin of DNA replication is located upstream of the chicken Mcm4 gene}

To investigate whether the intergenic region between Mcm4 and Prkdc also acts as a DNA replication origin in chicken cells we performed nascent strand abundance assays as described by Giacca et al. [26]. The nascent strand abundance assay is a powerful and widely used 

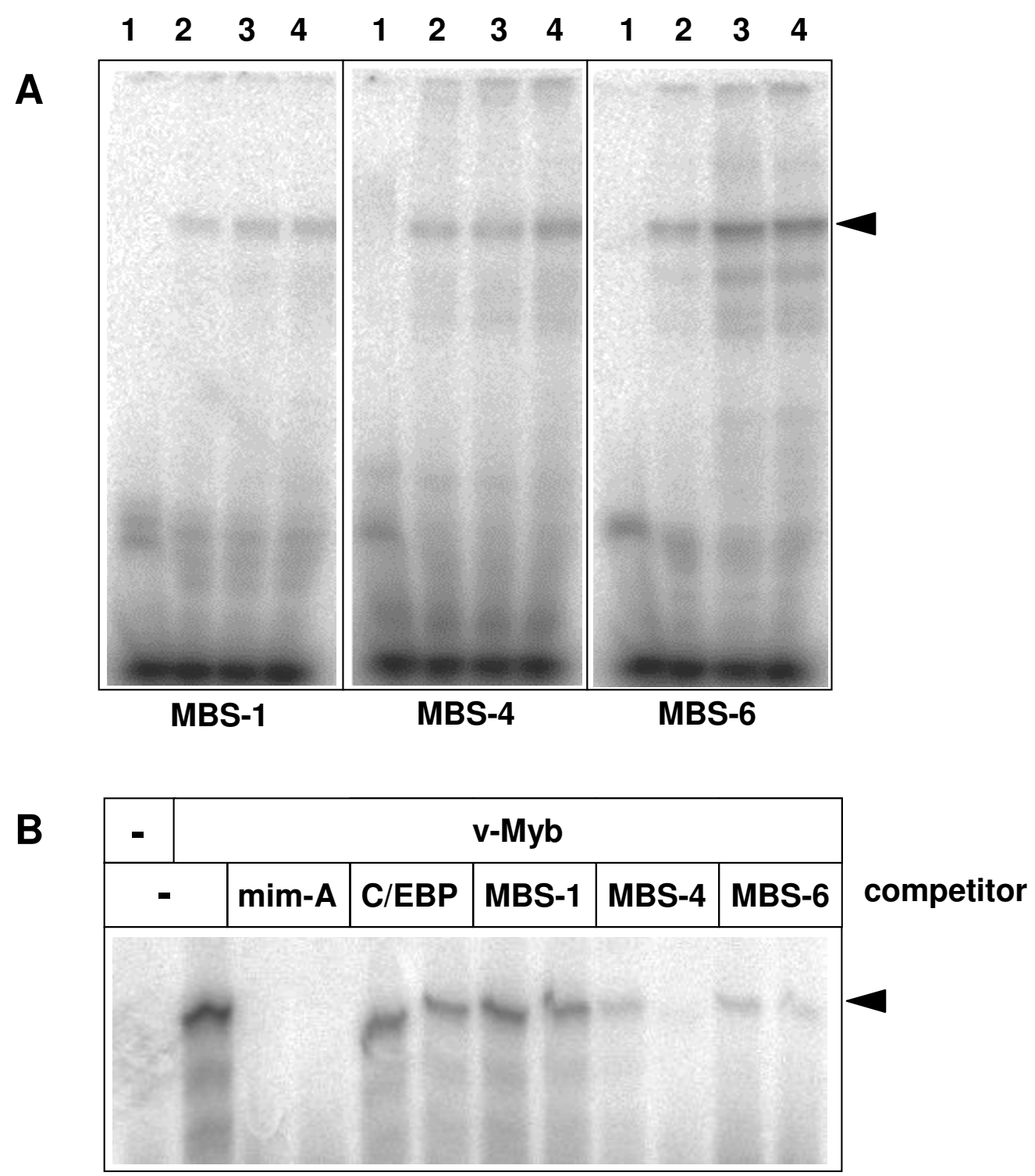

\section{Figure 2}

$\mathrm{v}$-Myb binds to the $\mathrm{Mcm} 4$ promoter region in vitro. A. Electrophoretic mobility shift experiments were performed using bacterially expressed full-length v-Myb protein and radiolabeled oligonucleotides corresponding to Myb binding sites MBS-I, MBS-4 and MBS-6. Binding reactions were performed without Myb protein (lanes I) or with increasing amounts of v-Myb (lanes 2 to 4). Complexes of full-length v-Myb and the oligonucleotides are marked by an arrowhead. The band at the bottom corresponds to unbound oligonucleotides. B. Radiolabeled oligonucleotide containing the Myb binding site A of the mim-I promoter were incubated with bacterially expressed full-length $\mathrm{v}-\mathrm{Myb}$ and excess of unlabeled competitor oligonucleotides, as indicated at the top. Competitors were used at 40 -fold or 80 -fold molar excess of unlabeled over labeled oligonucleotide, respectively. Only the upper part of the gel containing the complex of v-Myb and the radioactive oligonucleotide is shown. 


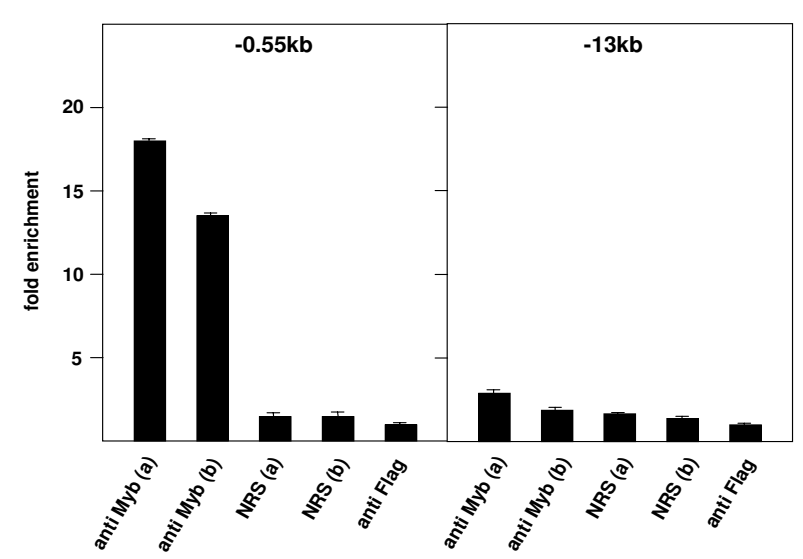

Figure 3

Chromatin immunoprecipitation of the $\mathrm{Mcm} 4$ promoter region. Chromatin fragments prepared from BM2 cells were subjected to immunoprecipitation using two different Myb-specific rabbit antisera raised against the DNAbinding domain of v-Myb (anti Myb a and b). Control immunoprecipitations were performed with two different batches of normal rabbit serum (NRS a and b) or anti-Flag antibodies (anti Flag). DNA isolated from the immunoprecipitates was analyzed by quantitative real-time PCR using primers specific for the $\mathrm{Mcm} 4$ promoter region $(-0.55 \mathrm{~kb}$, left panel) or for a region approximately $13 \mathrm{~kb}$ upstream of the $\mathrm{Mcm} 4$ gene $(-\mathrm{I} 3$ $\mathrm{kb}$, right panel). The columns indicate the amount of PCR product obtained relative to the anti-Flag control reaction.

method to identify and map DNA replication origins. The assay is based on the isolation and quantification of single stranded DNA 1-2 kb in length (so-called nascent DNA) which is primarily derived from replication origin regions. The method can be performed with asynchronously growing cells and does not depend on the availability of antisera against origin binding proteins (such as Orc- or MCMproteins). Briefly, nascent DNA 1-2 kb in length was isolated from different chicken cells by sucrose gradient sedimentation. Sets of primers mapping to the intergenic region as well as to upstream and downstream sequences were used to determine the abundance of the corresponding sequences in nascent DNA using quantitative realtime PCR. BM2 cells are myeloid v-myb transformed cells that express high levels of the v-Myb protein. HD11 cells are myeloid cells that do not express $\mathrm{v}-\mathrm{Myb}$ or $\mathrm{c}-\mathrm{Myb}$. DT40 is a line of B-lymphoid cells that express c-Myb. Finally, we used a subclone of the DT40 line in which the c-myb gene had been disrupted by homologous recombination [27]. As illustrated in Fig. 5 the Mcm4-Prkdc intergenic region was enriched in nascent DNA in each of these cell lines. This demonstrated that this region acts as a DNA

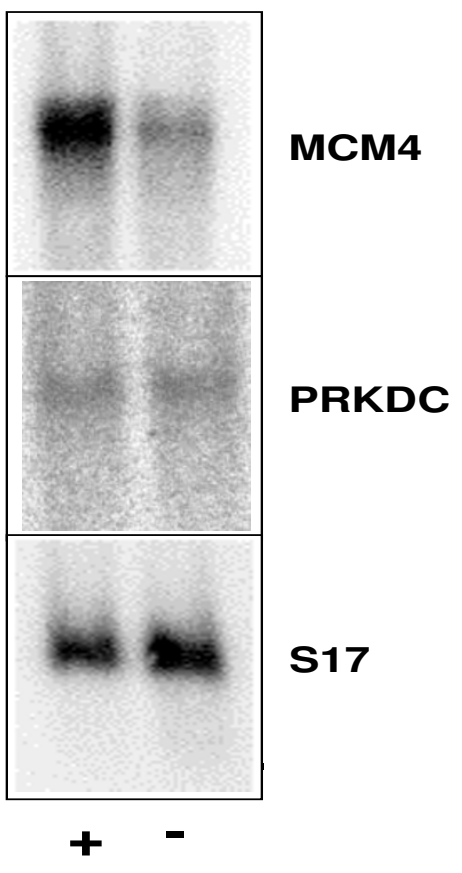

\section{Figure 4}

The chicken $\mathbf{M c m} 4$ gene is regulated by $\mathrm{v}$-Myb. Polyadenylated RNA from 10.4 cells grown for 24 hours in the presence (+ lanes) or absence (- lanes) of $2 \mu \mathrm{M} \beta$-estradiol was analyzed by Northern blotting using probes specific for Mcm4, Prkdc or SI 7 mRNA.

replication origin also in chicken cells. We did not observe significant differences in the abundance of the origin region between myeloid cells expressing (BM2) or not expressing (HD11) v-Myb. Although the abundance of the origin region was higher in DT40 cells compared to myeloid cells, there was no significant difference between wild-type and c-Myb deficient DT40 cells. Thus, although Myb binds to the intergenic region and stimulates $\mathrm{Mcm} 4$ expression, it does not affect the activity of the replication origin.

\section{Identification of an origin of DNA-replication in the promoter region of the chicken adenosine receptor $2 B$ gene}

We also examined the promoters of two known Myb-regulated genes, the mim- 1 and adenosine $2 \mathrm{~B}$ receptor genes, for replication origin activity. Both genes are direct Myb targets and their promoters have been analyzed in detail 
A
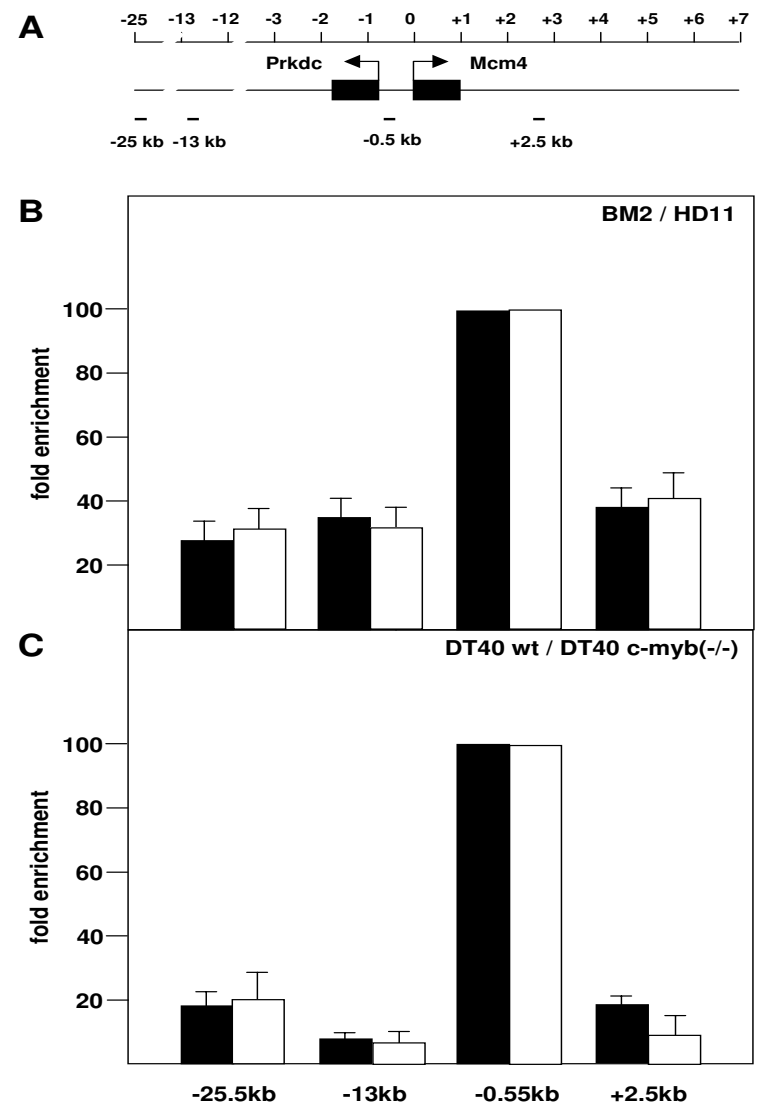

\section{Figure 5}

Replication origin activity of the Mcm4-Prkdc intergenic region in chicken cells. A. Schematic illustration of the Mcm4-Prkdc intergenic region. The black boxes and the arrows denote the transcriptional start sites of both genes. The positions of primer pairs used in the PCR analysis are shown below. The scale at the top is in kilobases. B. Nascent strand abundance assay. For quantification, real-time PCR was performed using the primer pairs indicated at the bottom. The columns show the average abundance of the corresponding sequences in nascent strand preparations of BM2 (black columns) or HDI I (white columns) cells relative to the sequences amplified with the $-0.5 \mathrm{~kb}$ primer pair. Error bars mark the standard deviations. C. Nascent strand abundance analysis of the $\mathrm{Mcm} 4$ promoter region using wild-type (black columns) or c-myb deficient (white columns) DT40 cells.

[5,14,28-30]. Nascent DNA from different cell lines was analyzed using sets of primers spanning a region from -5 $\mathrm{kb}$ to $+5 \mathrm{~kb}$ around the promoter in case of the mim-1 gene and from $-3.2 \mathrm{~kb}$ to $+4.8 \mathrm{~kb}$ around the promoter of the $\mathrm{A} 2 \mathrm{~B}$ receptor gene. We did not observe enrichment of mim-1 promoter sequences in preparations of nascent DNA, indicating the mim-1 promoter does not coincide with a DNA replication origin (data not shown). By contrast, the promoter region of the $\mathrm{A} 2 \mathrm{~B}$ receptor gene was enriched in nascent DNA, suggesting that an origin of DNA-replication is located at the 5 ' end of the A2B receptor gene (Fig. 6). As in the case of the Mcm4 replication origin we did not observe significant differences in origin activity of the promoter region of the $\mathrm{A} 2 \mathrm{~B}$ receptor gene between the different cell lines.

\section{Discussion}

The identification of the chicken Gas41 gene, whose promoter region functions as a DNA replication origin, as a bona fide Myb target gene [20] has raised the question whether the co-localization of a Myb-regulated promoter with a replication origin is just a rare coincidence or a more common phenomenon? To address this question we used two different strategies: i.) We examined the promoter regions of known Myb-regulated genes for replication origin activity using the nascent strand abundance assay. ii.) We investigated the activity of $\mathrm{v}-\mathrm{Myb}$ at the Mcm4-Prkdc intergenic region, which harbors several potential Myb binding sites and is associated with a replication origin in human cells [22].

Analysis of the adenosine receptor 2B gene, a known Myb target gene $[14,30]$, showed that the sequences around the 5 ' end of the gene were enriched in preparations of nascent DNA. This observation strongly suggested that the promoter of the A2B receptor co-localizes with a DNA replication origin. A further case of such co-localization was revealed by the analysis of the Mcm4-Prkdc intergenic region. Our data showed that $\mathrm{v}-\mathrm{Myb}$ binds to this region both in vitro and in vivo and stimulates transcription of the chicken Mcm4 gene. Furthermore, we demonstrated that the Mcm4-Prkdc intergenic region is a replication origin also in chicken cells. Thus, chicken Mcm4 is a novel vMyb target gene whose promoter region is also associated with a DNA replication origin. As these examples show, Myb-regulated genes and replication origins co-localize in some cases. However, it is also evident from the limited number of genes that have been analyzed so far that not every Myb target gene promoter is associated with a replication origin. For example, the promoter region of the mim-1 gene does not possess replication origin activity.

In the light of the co-localization of replication origins with several promoters containing clusters of Myb binding sites we wondered how frequently such clusters occur in the chicken genome. We screened approximately three million basepairs of randomly selected chicken genomic sequences for the presence of clusters of Myb binding motifs (AACG or AACTG) that are similar to those found at the MCM4, Adora2b and Gas41 replication origins. 
A

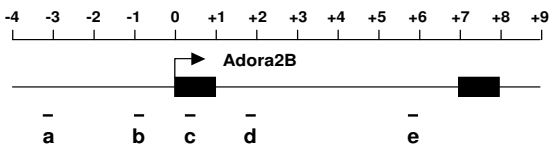

B

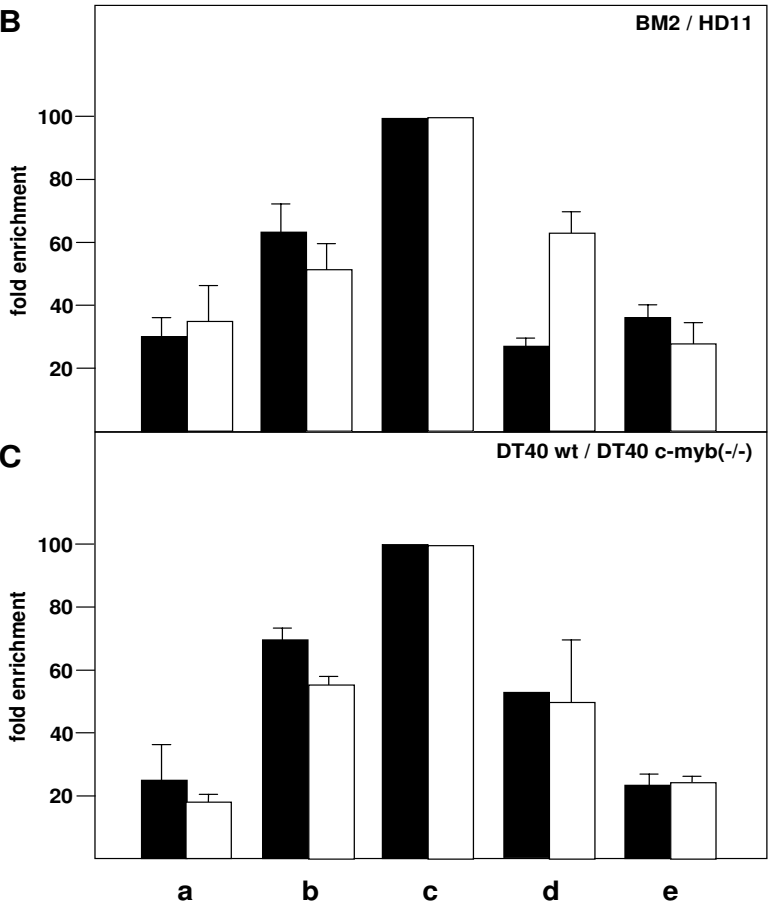

Figure 6

Replication origin activity of the promoter region of the chicken adenosine receptor $2 B$ gene. A. Schematic illustration of the chicken $A 2 B$ receptor gene. The black boxes show the two exons of the gene. The transcriptional start site is marked by an arrow. The position of primer pairs used in the PCR analysis is shown below. The scale at the top is in kilobases. B. Nascent strand abundance assay of the adenosine receptor $2 \mathrm{~B}$ promoter region using the $\mathrm{PCR}$ primer pairs indicated at the bottom. The columns show the average abundance of the corresponding sequences in nascent strand preparations of BM2 (black columns) or HDII (white columns) cells relative to the sequences amplified with the -3.9 $\mathrm{kb}$ primer pair. Error bars mark the standard deviations. $\mathbf{C}$. Nascent strand abundance analysis of the promoter region using wild-type (black columns) or c-myb deficient (white columns) DT40 cells.

While on the average one such motif is present per 200 base pairs we found that clusters of at least six of such sites within stretches of 250 base pairs occur only once per approximately $25 \mathrm{~kb}$. Although the number of such binding motif clusters is higher than the estimated number of replication origins in the chicken genome (one replication origin per approximately $100 \mathrm{~kb}$, as extrapolated from mammalian cells $[31,32])$, it appears unlikely that the concurrence of clusters of Myb binding motifs and DNA replication origins reported here is purely accidental. It will therefore be interesting to examine such clusters of Myb binding motifs for their potential role as replication origins.

The functional consequences, if any, of such co-localization are unclear at present. We have not observed that vMyb or c-Myb influence the activity of the replication origins identified here. $\mathrm{v}-\mathrm{Myb}$ or $\mathrm{c}-\mathrm{Myb}$, therefore, appear not to be involved in the control of origin activity. Recent work on the Myb homolog (Dm-Myb) of Drosophila melanogaster has provided evidence that Dm-Myb performs a non-transcriptional role in the control of the replication origin responsible for chorion gene amplification [21]. Furthermore, it has been shown that some of the phenotypic consequences of mutation of Dm-Myb can be compensated by B-Myb, but not by c-Myb or A-Myb [33]. It is therefore conceivable that B-Myb plays a role at the replication origins identified here. Another interesting possibility is that rather than being regulated by Myb the presence of a replication origin might affect the activation of the associated gene by Myb. For example, compacted chromatin structures will be opened during replication thereby providing transcription factors access to the DNA. It is therefore possible that the association with a replication origin imposes an additional level of control onto the adjacent gene, which would be expected to be cell cycle dependent. It is presently not known whether the Mcm4 and Adora2B genes are expressed in a cell cycle dependent manner. However, in this respect it is interesting to note that the phenotypic changes of myeloid cells transformed by a temperature-sensitive version of v-Myb that accompany activation of v-Myb by down-shifting the cells from the non-permissive to the permissive temperature were not observed when DNA replication was inhibited [34]. This observation is consistent with the idea that the activation of at least some Myb-regulated genes depends on DNA replication. Clearly, further work is necessary until we can discern which of these possibilities, if any, is right.

Independent of a possible role of DNA replication origins in Myb-inducible gene expression our work is also of interest because we have identified two novel replication origins in chicken cells. So far, only very few replication origins are known in chicken cells, such as the origins located in the alpha and beta globin gene clusters $[35,36]$ and between the lysozyme and Gas41 genes $[18,19]$. It is also interesting to note that the origin in the Mcm4-Prkdc intergenic region has been conserved between between chickens and humans.

Another interesting aspect of our work is the identification of the chicken Mcm4 gene as a Myb-regulated gene. $\mathrm{MCM} 4$, together with other MCM proteins, forms the hex- 
americ MCM2-7 complex which functions as helicase during the S-phase of the cell cycle. The MCM2-7 complex is loaded onto the DNA prior to the initiation of DNA replication and constitutes an essential part of the pre-replication complex [for reviews see: [37-39]]. In addition to acting as a helicase in concert with the other MCM proteins forming the MCM2-7 complex there is evidence that MCM4 also performs a specific regulatory role. MCM4 is extensively phosphorylated when cells are exposed to inhibitors of DNA synthesis or to UV irradiation, leading to a block of DNA fork progression $[40,41]$, suggesting that MCM4 plays a role in the DNA replication block checkpoint system. In the normal course of the cell cycle MCM4 is phosphorylated by Cdk2, leading to the inhibition of the helicase function of the MCM complex $[42,43]$. Blockage of this phosphorylation leads to reinitiation of replication and genomic instability. These observations suggest that MCM4 is a key component of the MCM complex whose manipulation can influence the control of DNA replication and genomic stability. Interestingly, elevated Mcm4 mRNA levels have been found in certain tumors, suggesting that increased Mcm4 expression can contribute to the malignant properties of the tumor cells [44,45]. Recently, a hypomorph allele of mouse Mcm4 was identified and shown to cause chromosomal instability [46]. Thus, Mcm4 is an interesting novel Myb target gene that provides a possible link between Myb, DNA-replication and checkpoint control.

\section{Conclusion}

We have identified the chicken Mcm4 gene as a novel Myb-regulated gene and shown that the Mcm4 promoter region is associated with an origin of DNA replication. Similarly, our work shows that the promoter of the Mybregulated adenosine receptor $2 \mathrm{~B}$ gene co-localizes with a replication origin. Our work raises the possibility that a fraction of Myb target gene promoters is associated with DNA replication origins.

\section{Methods}

\section{Cell culture}

The BM2 and HD11 are lines of AMV-transformed chicken myeloblasts and MC29-transformed macrophages that were originally obtained from C. Moscovici and T. Graf, respectively. BM2 cells were grown in RPMI 1640 medium supplemented with $5 \%$ fetal calf serum, 5 $\%$ chicken serum and $10 \%$ tryptone phosphate broth (Gibco). HD11 cells were grown in basal Iscoves' medium supplemented with $8 \%$ fetal calf serum and $2 \%$ chicken serum. 10.4 is a derivative of the HD11 cell line expressing a v-Myb/ER fusion protein [25]. 10.4 cells were grown in the same medium as HD11 cells. To activate the v-Myb/ER fusion protein the growth medium was supplemented with $2 \mu \mathrm{M} \beta$-estradiol for 24 hours.

\section{Northern blotting}

Preparation of polyadenylated RNA and Northern blotting were performed as described [25]. Mcm4 and Prkdc mRNAs were detected using cDNA clones of chicken Mcm4 (riken1_3305r1) and Prkdc (riken1_9d19r2), kindly provided by H. Arakawa and J.M. Buerstedde. As an internal control a specific probe for the ribosomal $S 17$ gene was used.

\section{Electrophoretic mobility shift assay}

The following pairs of single-stranded oligonucleotides were annealed and used for electrophoretic mobility shift assays:

MCM4-MBS-1_sense: CAGTCCGAGGGG-3',

MCM4-MBS-1_anti: CCAACGCTGCCCGG-3',

MCM4-MBS-4_sense: GCGCGTCCCCC-3',

MCM4-MBS-4_anti: 5'-GGGGGGACGCGCCGTTCGACCCACGGCG-3',

MCM4-MBS-6_sense: CTACCG-3',

MCM4-MBS-6_anti: GGCAGCGCTA-3'.

Mim-1A_sense: 5'-GCTCTAAAAAACCGTTATAATGTACAGATATCTT-3'

Mim-1A_anti: 5'-AAGATATCTGTACATTATAACGGTTTTTTAGAG-3'.

C/EBP_sense: 5'-CTGGCTCGGTTCTTTCACAACCACACATCC-3'

C/EBP_antisense: 5'- GGGATGTGTGGTTGTGAAAGAACCGAGCCAG-3'

After annealing, the oligonucleotides were radiolabeled by filling-in the ends using Klenow polymerase and $\alpha^{32} \mathrm{P}$ dCTP. Preparation of bacterial full-length v-Myb protein and binding experiments were performed as described [47].

\section{Chromatin immunoprecipitation}

Approximately $10^{8} \mathrm{BM} 2$ cells were incubated in $1 / 10$ cross-linking solution containing $0.1 \mathrm{M} \mathrm{NaCl} ; 1 \mathrm{mM}$ EDTA; 0.5 mM EGTA; $50 \mathrm{mM}$ Tris- $\mathrm{HCl}$, pH 8.0 and $11 \%$ formaldehyde for $10 \mathrm{~min}$ and quenched for $5 \mathrm{~min}$ in 125 
mM glycine. After washing in ice-cold phosphate-buffered saline, cells were treated for $20 \mathrm{~min}$ each with washing solution A (0.25\% Triton X100; $10 \mathrm{mM}$ Tris- $\mathrm{HCl}$, pH8.0, $10 \mathrm{mM}$ EDTA; $0.5 \mathrm{mM}$ EGTA) and B (200 mM NaCl; 10 mM Tris-HCl, pH8.0; 1 mM EDTA; 0.5 mM EGTA). Nuclei were sonicated on ice ( 4 times for $20 \mathrm{sec}$ in 2 min intervals) in egg lysis buffer (ELB) (120 mM NaCl; 50 mM Tris$\mathrm{HCl}$, pH7.5; 20 mM NaF; 1 mM EDTA; 6 mM EGTA; 15 $\mathrm{mM}$ sodiumpyrophosphate; $1 \mathrm{mM}$ phenylmethylsulfonyl fluoride and $0.1 \%$ Nonidet P-40). DNA-protein complexes were incubated with two different Myb-specific antibodies raised against the DNA-binding domain of vMyb [48], normal rabbit serum or anti-Flag antibody (Sigma). After precipitation with protein-A-sepharose the samples were washed several times in ELB buffer. Following elution with $0.5 \%$ SDS the DNA was recovered by reverse-crosslinking for $6 \mathrm{~h}$ at $37^{\circ} \mathrm{C}$ and $65^{\circ} \mathrm{C}$, respectively, in a buffer containing $0.5 \%$ SDS; $10 \mathrm{mM}$ DTT and $100 \mu \mathrm{g}$ proteinase $\mathrm{K}$. The immunoprecipitated DNA was then purified by phenol-chloroform extraction and ethanol precipitation. PCR-amplification was performed by quantitative real-time PCR using primers specific for the chicken MCM4 promoter region $(-0.55 \mathrm{~kb})$ or primers derived from the $-13 \mathrm{~kb}$ region of the gene.

\section{Nascent strand abundance assay}

Analysis of replication origin activity was performed according to Giacca et al. [26]. Total genomic DNA was isolated from approximately $10^{8}$ exponentially growing HD11 or BM2 cells using the Nucleobond CB kit (Macherey \& Nagel) following the manufacturer's instructions. DNA was resuspended in TNE buffer (10 mM Tris, $\mathrm{pH} 8.0$; $100 \mathrm{mM} \mathrm{NaCl} ; 1 \mathrm{mM}$ EDTA) and heat-denatured for 7 min at $95^{\circ} \mathrm{C}$ followed by rapid cooling on ice. Denatured DNA was layered on a linear neutral sucrose gradient (5$30 \%$ in TNE) and size fractionated by centrifugation in a Beckman SW28 rotor at $26.000 \mathrm{rpm}$ for $20 \mathrm{~h}$ at $20^{\circ} \mathrm{C}$. Nascent strand DNA fractions with an average DNA size of $1-1.5 \mathrm{~kb}$ were pooled, precipitated with ethanol and and treated with T4-polynucleotide kinase and $\lambda$-exonuclease as described previously $[49,50]$. The purified nascent DNA strands were analyzed by quantitative real-time PCR using the following primer pairs:

A2B_-3.2kb_for 5'-TGTCCGCAGAGCAGTTCAG-3';

A2B_-3.2kb_rev 5'-GCAGAACTGGCACAGCTTTCT-3';

A2B_-0.9kb_for 5'-GGTGTTATTGGATAGGCGCTG-3';

A2B_-0.9kb_rev 5'-CACAAAAACATGAGGCAATCG-3';

A2B_+0.4kb_for 5'-CCCATCCCACCTCTCTCGT-3';

A2B_+0.4kb_rev 5'-CACCTTCACCATTGTCGCC-3';
A2B_+1.75kb_for 5'-CCTGGAGTGGGCTTTGACA-3';

A2B_+1.75kb_rev 5'-GCCCTGTTCCCATCCTTGTA-3';

A2B_+4.8kb_for 5'-AAGGTAATGCTGCGACGTCA-3';

A2B_+4.8kb_rev 5'-GTGAAAGCCACACGGAGCTA-3';

MCM4_-13kb_for 5'-CAGCCAGCAAACAGCACTATTTC3';

MCM4_-13kb_rev 5'-GGCCTTGCTTTCACCTAAGTCA-3';

MCM4_-0.55kb_for 5'-TAGACGACTTTCCGGAGA-

GACAGA-3';

MCM4_-0.55kb_rev 5'-CGCTGGGCGAATCGTTT-3';

MCM4_+2.5kb_for 5'-CATGGCTGCCAATGAGATCT-3';

MCM4_+2.5kb_rev 5'-GGCCGTACTTGAATTTGATGTTC$3^{\prime}$.

\section{Real-time PCR quantification}

Q-PCR was carried out on a GeneAmp 5700 SDS (Applied Biosystems) with the qPCR Core kit for SYBR Green I (Eurogentec) following the instructions of the manufacturers. Primers were chosen with PrimerExpress 2.0 Software (Applied Biosystems). As DNA standard we used sonicated total genomic chicken DNA (average size 1 to 5 $\mathrm{kb})$ serially diluted to 50.000, 10.000, 2.000, 400 and 80 genomic equivalents per reaction $(1$ genomic equivalent $=$ $1.25 \times 10^{-12} \mathrm{~g}$ ). To produce a calibration curve, the $\mathrm{C}_{\mathrm{T}}$ value of each sample was plotted against the logarithm of its concentration. The number of genomic equivalents of each target sequence in the nascent DNA strand samples was then determined by extrapolation from the calibration curve. Several conditions were met by each assayed sample: The slope of the standard curve was around 3 to 3.5 (indicating a PCR efficiency close to $100 \%$ ). The sample was diluted such that its genomic equivalents fell within the central part of the calibration curve. The melting curve profile showed a single PCR product. The specificity of the PCR products was additionally confirmed for each primer pair by agarose gel electrophoresis.

\section{Authors' contributions}

HG carried out the in vitro DNA binding and nascent strand abundance assays. DB performed the chromatin immunoprecipitations and northern blot experiments. KHK conceived the study, participated in its design and prepared the manuscript. All authors read and approved the final manuscript. 


\section{Acknowledgements}

We thank H. Arakawa and J.-M. Buerstedde for providing plasmids. This work was supported by a grant from the DFG (KL46I/I0-I).

\section{References}

I. Lipsick JS, Wang DM: Transformation by v-Myb. Oncogene 1999, I 8:3047-3055.

2. Oh I-H, Reddy EP: The myb gene family in cell growth, differentiation and apoptosis. Oncogene 1999, 18:3017-3033.

3. Weston K: Myb proteins in life, death and differentiation. Cur Opin Genet Dev 1998, 8:76-8I.

4. Biedenkapp H, Borgmeyer U, Sippel AE, Klempnauer K-H: Viral myb oncogene encodes a sequence-specific DNA-binding activity. Nature 1988, 355:835-837.

5. Ness SA, Marknell A, Graf T: The v-myb oncogene product binds to and activates the promyelocyte-specific mim-I gene. Cell 1989, 59: I I I5-I I25.

6. Introna M, Golay J, Frampton J, Nakano T, Ness SA, Graf T: Mutations in v-myb alter the differentiation of myelomonocytic cells transformed by the oncogene. Cell 1990, 63:1287-1297.

7. Frampton J, Ramqvist T, Graf T: v-Myb of E26 leukemia virus upregulates bcl-2 and suppresses apoptosis in myeloid cells. Genes Dev 1996, I0:2720-273।.

8. Taylor $\mathrm{D}$, Badiani $\mathrm{P}$, Weston $\mathrm{K}$ : A dominant interfering Myb mutant causes apoptosis in $T$ cells. Genes Dev 1996 , I 0:2732-2744.

9. Burk O, Worpenberg S, Haenig B, Klempnauer K-H: tom- I, a novel v-Myb target gene expressed in AMV- and E26-transformed myelomonocytic cells. EMBO J | 997, I 6: | 37| - I380.

10. Hogg A, Schirm S, Nakagoshi H, Bartley P, Ishii S, Bishop JM, Gonda $\mathrm{T}$ ]: Inactivation of a c-Myb/estrogen receptor fusion protein in transformed primary cells leads to granulocyte/macrophage differentiation and down regulation of c-kit but not cmyc or cdc2. Oncogene 1997, 1 5:2885-2898.

II. Kowenz-Leutz E, Herr P, Niss K, Leutz A: The homeobox gene GBX2, a target of the myb oncogene, mediates autocrine growth and monocyte differentiation. Cell |997, 9I:|85-195.

12. Schlichter U, Burk O, Worpenberg S, Klempnauer K-H: The chicken Pdcd4 gene is regulated by v-Myb. Oncogene 2001 , 20:231-239.

13. Oelgeschläger $M$, Nuchprayoon I, Lüscher B, Friedman AD: C/EBP, $c-M y b$, and PU.I cooperate to regulate the neutrophil elastase promoter. Mol Cell Biol 1996, 16:4717-4725.

14. Worpenberg S, Burk O, Klempnauer K-H: The chicken adenosine receptor 2B gene is regulated by v-myb. Oncogene 1997, I 5:213-22|.

15. Rushton J, Davis LM, Lei W, Mo X, Leutz A, Ness SA: Distinct changes in gene expression induced by A-Myb, B-Myb and cMyb proteins. Oncogene 2003, 22:308-313.

16. Chayka O, Kintscher J, Braas D, Klempnauer K-H: v-Myb mediates cooperation of a cell-specific enhancer with the mim-I promoter. Mol Cell Biol 2005, 25:499-5II.

17. Kintscher J, Yamkamon V, Braas D, Klempnauer K-H: Identification of a Myb-responsive enhancer of the chicken C/EBPbeta gene. Oncogene 2004, 23:5807-58I4.

18. Phi-van L, Sellke C, von Bodenhausen A, Stratling WH: An initiation zone of chromosomal DNA replication at the chicken lysozyme gene locus. J Biol Chem 1998, 273: I8300-I8307.

19. Phi-van L, Stratling WH: An origin of bidirectional DNA replication is located within a CpG island at the 3" end of the chicken lysozyme gene. Nucleic Acids Res 1999, 27:3009-3017.

20. Braas $D$, Gundelach H, Klempnauer $\mathrm{K}-\mathrm{H}$ : The glioma-amplified sequence $4 \mathrm{I}$ gene (GAS4I) is a direct Myb target gene. Nucleic Acids Res 2004, 32:4750-4757.

21. Beall EL, Manak JR, Zhou S, Bell M, Lipsick JS, Botchan MR: Role for Drosophila Myb-containing protein complex in site-specific DNA replication. Nature 2002, 420:833-837.

22. Ladenburger EM, Keller C, Knippers R: Identification of a binding region for human origin recognition complex proteins $I$ and 2 that coincides with an origin of DNA replication. $\mathrm{Mol} \mathrm{Cell} \mathrm{Biol}$ 2002, 22: 1036-1048.

23. Connelly MA, Zhang $\mathrm{H}$, Kieleczawa J, Anderson CW: The promoters for human DNA-PKcs (PRKDC) and MCM4: divergently transcribed genes located at chromosome 8 band qII. Genomics 1998, 47:71-83.
24. Fujimori A, Hashimoto $H$, Araki R, Daito $T$, Sato $S$, Kasama $Y$, Tsutsumi $Y$, Mori M, Fukumura R, Ohhata T, Tatsumi K, Abe $M$ : Sequence analysis of 193.4 and $83.9 \mathrm{kbp}$ of mouse and chicken genomic DNAs containing the entire Prkdc (DNAPKcs) gene. Radiat Res 2002, I 57:298-305

25. Burk O, Klempnauer $\mathrm{K}-\mathrm{H}$ : Estrogen-dependent alterations in differentiation state of myeloid cells caused by a v-myb/ estrogen receptor fusion protein. EMBO J 1991, 1 0:3713-3719.

26. Giacca M, Pelizon C, Falaschi A: Mapping replication origins by quantifying relative abundance of nascent DNA strands using competitive polymerase chain reaction. Methods 1997, 13:3301-312

27. Appl H, Klempnauer K-H: Targeted disruption of c-myb in the chicken preB-cell line DT40. Oncogene 2002, 2 I:3076-308I.

28. Ness SA, Kowenz-Leutz E, Casina T, Graf T, Leutz A: Myb and NF. $M:$ combinatorial activators of myeloid genes in heterologous cell types. Genes Dev 1993, 7:749-759.

29. Burk O, Mink S, Ringwald M, Klempnauer K-H: Synergistic activation of the chicken mim-I gene by v-myb and C/EBP transcription factors. EMBO J 1993, I 2:2027-2038.

30. Kattmann D, Klempnauer K-H: Identification and characterization of the Myb-inducible promoter of the chicken adenosine receptor 2B gene. Oncogene 2002, 2 I:4663-4672.

31. Jackson DA, Pombo A: Replicon clusters are stable units of chromosome structure: evidence that nuclear organization contributes to the efficient activation and propagation of $\mathbf{S}$ phase in human cells. J Cell Biol I998, I 40: I 285- I 295.

32. Berezney R, Dubey DD, Huberman JA: Heterogeneity of eukaryotic replicons, replicon clusters, and replication foci. Chromosoma 2000, 108:47|-484.

33. Davidson C, Tirouvanziam R, Herzenberg L, Lipsick J: Functional evolution of the vertebrate Myb gene family: B-Myb, but neither A-Myb nor c-Myb, complements Drosophila Myb in hemocytes. Genetics 2004, 169:215-229.

34. Beug H, Blundell PA, Graf T: Reversibility of differentiation and proliferative capacity in avian myelomonocytic cells transformed by tsE26 leukemia virus. Genes Dev 1987, I:277-286.

35. Prioleau MN, Gendron MC, Hyrien O: Replication of the chicken beta-globin locus: early-firing origins at the 5' HS4 insulator and the rho- and betaA-globin genes show opposite epigenetic modifications. Mol Cell Biol 2003, 23:3536-3549.

36. Verbovaia L, Razin SV: Analysis of the replication direction through the domain of alpha-globin-encoding chicken genes. Gene 1995, 166:255-259.

37. Bell SP, Dutta A: DNA replication in eukaryotic cells. Annu Rev Biochem 2002, 71:333-734.

38. Stillman B: Origin recognition and the chromosome cycle. FEBS letters 2005, 579:877-884.

39. Takeda DY, Dutta A: DNA replication and progression through S phase. Oncogene 2005, 24:2827-2843.

40. Ishimi Y, Komamura-Kohno Y, Kwon HJ, Yamada K, Nakanishi M: Identification of MCM4 as a target of the DNA replication block checkpoint system. J Biol Chem 2003, 278:24644-24650.

4I. Ishimi Y, Komamura-Kohno Y, Karasawa-Shimizu K, Yamada K: Levels of MCM4 phosphorylation and DNA synthesis in DNA replication block checkpoint control. J Struct Biol 2004, | 46:234-24l.

42. Hendrickson M, Madine M, Dalton S, Gautier J: Phosphorylation of MCM4 by cdc2 protein kinase inhibits the activity of the minichromosome maintenance complex. Proc Natl Acad Sci USA 1996, 93:12223-12228.

43. Zhu Y, Ishimi $Y$, Tanudji M, Lees E: Human CDK2 inhibition modifies the dynamics of chromatin-bound minichromosome maintenance complex and replication protein $A$. Cell Cycle 2005, 4: I 254-1263.

44. Ishimi Y, Okayasu I, Kato C, Kwon HJ, Kimura H, Yamada K, Song SY: Enhanced expression of $\mathrm{Mcm}$ proteins in cancer cells derived from uterine cervix. Eur J Biochem 2003, 270:1089-I I0I.

45. Huang XP, Rong TH, Wu QL, Fu JH, Yang H, Zhao JM, Fang Y: MCM4 expression in esophageal cancer from southern China and its clinical significance. J Cancer Res Clin Oncol 2005, I 3 I:677-682.

46. Shima N, Alcaraz A, Liachko I, Buske TR, Andrews CA, Munroe RJ, Hartford SA, Tye BK, Schimenti JC: A viable allele of $\mathbf{M c m} 4$ causes chromosome instability and mammary adenocarcinomas in mice. Nat Genet 2007, 39:93-98. 
47. Oehler T, Arnold H, Biedenkapp H, Klempnauer K-H: Characterization of the v-myb DNA binding domain. Nucleic Acids Res 1990, 18:1703-1710.

48. Klempnauer K-H, Bonifer C, Sippel AE: Identification and characterization of the protein encoded by the human c-myb proto-oncogene. EMBO J 1986, 5:|903-19|I.

49. Gerbi S, Bielinsky A-K: Replication initiation point mapping. Methods 1997, 13:27|-280.

50. Abdurashidova G, Deganuto M, Klima R, Riva S, Biamonti G, Giacca $M$, Falaschi A: Start sites of bidirectional DNA synthesis at the human lamin B2 origin. Science 2000, 287:2023-2026.

Publish with Bio Med Central and every scientist can read your work free of charge

"BioMed Central will be the most significant development for disseminating the results of biomedical research in our lifetime. "

Sir Paul Nurse, Cancer Research UK

Your research papers will be:

- available free of charge to the entire biomedical community

- peer reviewed and published immediately upon acceptance

- cited in PubMed and archived on PubMed Central

- yours - you keep the copyright

Submit your manuscript here:

http://www.biomedcentral.com/info/publishing_adv.asp
BioMedcentral 